\title{
Comparison of Bimaxillary Permanent Canine Arch Width in Terms of Human Sex Identification for Metric Analysis of Bite Marks
}

\section{Cakici B ${ }^{1}$, Aka PS ${ }^{2 *}$, Sevim Erol A $^{3}$ and Arıcı G ${ }^{4}$}

${ }^{1}$ Department of Forensic Anthropology, Institute of Health Sciences, University of Ankara, Turkey

${ }^{2}$ Department of Prosthodontics and Department of Forensic Medicine, Unit of Forensic Odontology, Faculty of Dentistry and Faculty of Medicine, University of Ankara, Head of Forensic Odontology Commission of Institute of Forensic Sciences, Ankara, Turkey

${ }^{3}$ Department of Anthropology, Faculty of Language, History and Geography, Forensic Anthropology Commission of Institute of Forensic Sciences, University of Ankara, Ankara, Turkey

${ }^{4}$ Department of Statistics, Faculty of Science and Literature, University of METU, Ankara, Turkey

\section{Abstract}

Bite marks analysis is an important issue of forensic sciences where the copies bite patterns are superimposed over the dental models and metric analysis is performed. These cases show a patterned injury, where the traces of six anterior teeth are usually present, among which the most prominent mark is found in the canine teeth area.

The purpose of this study is to demonstrate the sexual dimorphism from the bimaxillary inter canine arch width for both maxilla and mandibula. The study was conducted on the dental casts of 200 persons (100 female and 100 male) with an age average of 23 years. All measurements of this research were taken by first author, who measured the casts twice in different time intervals. The inter observer error of these measurements was calculated by descriptive statistics and the error value between the measurements was found insignificant for both maxilla and mandibula of females and males.

From the result of this research, the accurately diagnosed dimorphic inter canine teeth measurements and the undefined intersection areas were calculated for both maxilla and mandibula of females and males. These accurately diagnosed dimorphic measurements may lead the forensic expert to an easy and rapid sex identification result, in case the dental data of the specific population is known which the investigated person was affiliated.

Keywords: Bite marks; Inter canine arch width; Sexual dimorphism

\section{Introduction}

Bite marks analysis is one of the crucial issues of forensic sciences. This kind of scar traces are formed in the event of defense or assault by the teeth, which are the only weapon for human and animal species. Teeth are the hardest and the most durable biological material, which can resist against the post mortem degradation of the body, hence creates excellent evidences for forensic cases. Bite marks often have an impression of the six anterior teeth, where the most pronounced and the deepest marks being created by the canine teeth [1].

The time interval for canine teeth eruption is 16-20 months for primary dentition and 9-13 years for permanent dentition. Due to the 2014 OECD (Organization for Economic Co-operation and Development) database average life expectancy for girls is 82.9 and for boys is 77.3 years [2]. The average life span of canine teeth under normal hygienic conditions may be calculated as 7-10 years for primary canines, which exfoliate during 9-12 years and 64-73 years for permanent dentition according to life expectation data [3].

Bite mark identification process requires the shape and dimensions analysis of the traces left by the teeth. For some populations as South America Colombia Ticuna Indians, dental data as tooth size or inter-canine distance (ICD) may give unreliable results and make it unfeasible to identify by bite mark analysis $[4,5]$. However the canine teeth are usually easy to recognize from their triangular or trapezoidal marks and their dimorphic sizes [6-8]. In Turkey, both maxillary and mandibular canines show $77 \%$ sex difference than other teeth and the reason for this low ratio is due to the fact that sex discrimination in male dental models is less [9]. Studies conducted in India showed statistically significant higher mesio-distal dimensions of bimaxillary canine teeth for males than females $[10,11]$. The (ICD) of humans were found as 30 to $45 \mathrm{~mm}$ for males (36-42 $\mathrm{mm}$ for maxilla and 26-33 $\mathrm{mm}$ for mandible) and 25 to $45 \mathrm{~mm}$ for females where (34-41 $\mathrm{mm}$ for maxilla of $26-33 \mathrm{~mm}$ for mandible of females) for the 21-31 years age range of human samples [12]. The maxillary and mandibular canine tooth sizes and (ICD) were investigated in Suudi Arabia on 251 male and 252 females where both size were found larger for men however only the (ICD) was found statistically significant [13-15]. The purpose of this study was to determine the sexual dimorphism from the maxillary and mandibular (ICD).

\section{Method and Material}

This research was carried out on the dental casts of 100 female and 100 male, totally 200 case with an age average of 23 years. Measurements of the study were conducted twice, at different time intervals by the first author. Measurements were taken with Digital Vernier Caliper (MITUTOYO 7117057, Japan) with $0.1 \mathrm{~mm}$ precision (Figures 1A and $1 \mathrm{~B})$

\section{Results}

The possible differences between these measurements were calculated to find out the inter observer error value between the maxillary and mandibular measurements of the male and female cases. As shown in Table 1 the results were negligible $(0,02<\mathrm{P}<0,03)$. Descriptive statistical results of the measurements realized on

*Corresponding author: Aka PS, Prof. Dr. Retired Professor, Department of Prosthodontics and Department of Forensic Medicine, Unit of Forensic Odontology Faculty of Dentistry and Faculty of Medicine, University of Ankara, Head of Forensic Odontology Commission of Institute of Forensic Sciences, Ankara, Turkey, Tel: +90532 51363 89; E-mail: akasema@gmail.com

Received November 20, 2017; Accepted November 28, 2017; Published December 07, 2017

Citation: Cakici B, Aka PS, Sevim Erol A, Arıcı G (2017) Comparison of Bimaxillary Permanent Canine Arch Width in Terms of Human Sex Identification for Metric Analysis of Bite Marks. J Anthropology Rep 2: 116

Copyright: (C) 2017 Cakici B, et al. This is an open-access article distributed unde the terms of the Creative Commons Attribution License, which permits unrestricted use, distribution, and reproduction in any medium, provided the original author and source are credited. 
Citation: Cakici B, Aka PS, Sevim Erol A, Arıcı G (2017) Comparison of Bimaxillary Permanent Canine Arch Width in Terms of Human Sex Identification for Metric Analysis of Bite Marks. J Anthropology Rep 2: 116.

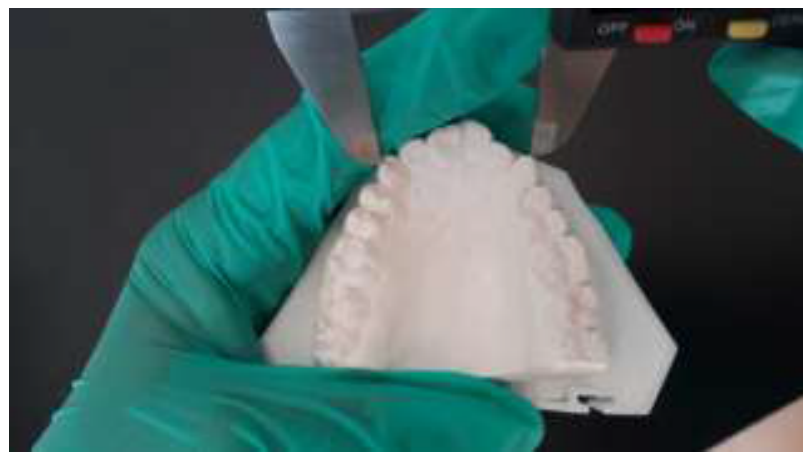

Figure 1A: Maxillary inter canine measurement.

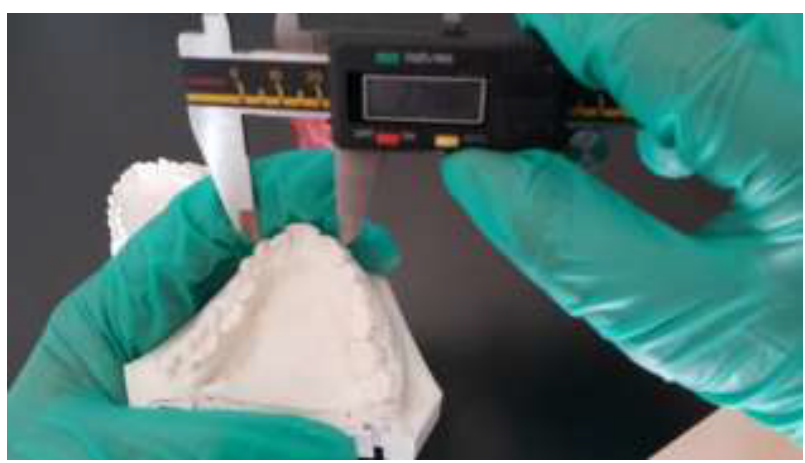

Figure 1B: Mandibular inter canine measurement.

\begin{tabular}{|l|c|c|c|c|}
\hline & $\begin{array}{c}\text { Female } \\
\text { Maxilla }\end{array}$ & $\begin{array}{c}\text { Female } \\
\text { Mandibula }\end{array}$ & $\begin{array}{c}\text { Male } \\
\text { Maxilla }\end{array}$ & $\begin{array}{c}\text { Male } \\
\text { Mandibula }\end{array}$ \\
\hline Number of Case N & 100 & 100 & 100 & 100 \\
\hline Std. Error of Mean & .03139 & .02619 & .02513 & .02312 \\
\hline
\end{tabular}

Table 1: Inter observer error.

\begin{tabular}{|l|c|c|c|c|}
\hline & $\begin{array}{c}\text { Number of } \\
\text { Case N }\end{array}$ & Range & Minimum & Maximum \\
\hline Female Maxilla & 100 & 7.07 & 30.24 & 37.30 \\
\hline Female Mandibula & 100 & 10.08 & 20.27 & 30.35 \\
\hline Male Maxilla & 100 & 10.50 & 32.88 & 41.15 \\
\hline Male Mandibula & 100 & 9.99 & 22.54 & 32.53 \\
\hline
\end{tabular}

Table 2: Descriptive statistics.

bimaxillary models of 200 individuals are seen (Table 2). The results of this research revealed that; in case the independent variable of maxillary (ICD) is in the range of $30.24<\mathrm{x}<32.88$ it can be said that this dental dimension belongs to a female; if the range is as $37.30<\mathrm{x}<41.15$ than this dental dimension belongs to a male. However if the measurement value is in the intersection of two sample groups as $32.89<\mathrm{x}<37.29$ as seen (Figure 2A) than the case cannot be diagnosed. Similarly in case the independent variable of mandibular (ICD) is in the range of $20.27<\mathrm{x}<22.54$ it can be said that this dental dimension belongs to a female; if the range is as $30.35<\mathrm{x}<32.53$ than this dental dimension belongs to a male. But if the measurement value is in the intersection of two sample groups as $22.55<\mathrm{x}<30.34$ and as seen in Figure $2 \mathrm{~B}$, than the case cannot be diagnosed.

The maxillary (ICD) is larger than the mandibular (ICD) both for males and females as shown in Table 3. This difference between male and female arch size is more pronounced for the maxilla.

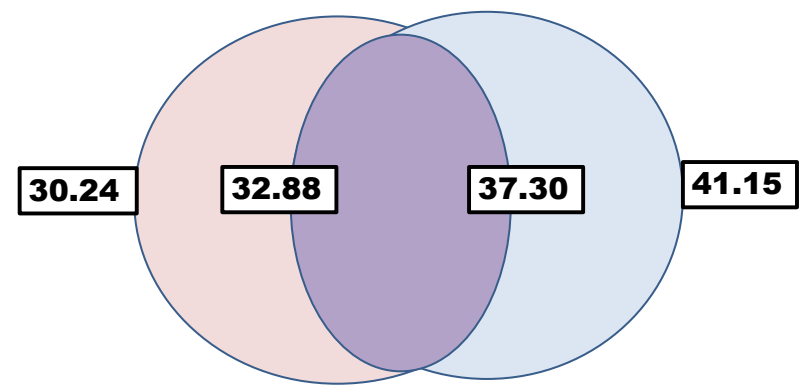

Figure 2A: Maxillary inter canine arch width is between $30.24-32.88 \mathrm{~mm}$ for females, $37.30-41.15 \mathrm{~mm}$ for males, but unpredictable between the intersection area $32.89-37.29 \mathrm{~mm}$.

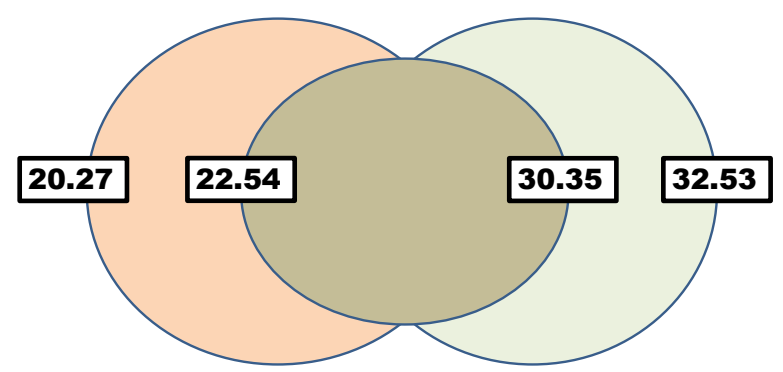

Figure 2B:Mandibular inter canine arch width is between $20.27-22.54 \mathrm{~mm}$ for females, $30.35-32.53 \mathrm{~mm}$ for males, but unpredictable between the intersection area $22.55-30.34 \mathrm{~mm}$.

\begin{tabular}{|l|c|c|}
\hline & Number of Cases & Averages \\
\hline Female Maxilla & 100 & $3,32,984$ \\
\hline Female Mandibula & 100 & $2,54,080$ \\
\hline Male Maxilla & 100 & $3,53,493$ \\
\hline Male Mandibula & 100 & $2,67,832$ \\
\hline
\end{tabular}

Table 3: Averages of measurements.

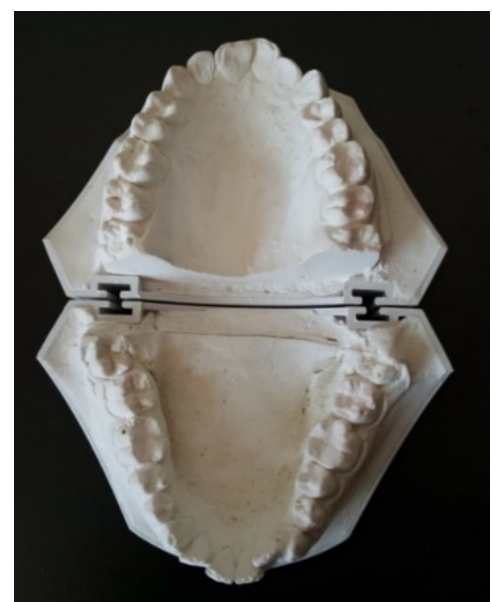

Figure 3: Different axis angles of canine teeth

In this research the difference between the minimum female and maximum male maxillary (ICD) was $10.91 \mathrm{~mm}$ and the undistinguished intersection dimension was $4.42 \mathrm{~mm}$. That is $41 \%$ of this dimension was undefinable, but $59 \%$ can be identified. Similarly the difference between the minimum female and maximum male mandibular (ICD) was $12.26 \mathrm{~mm}$ and the undistinguished intersection dimension was 
Citation: Cakici B, Aka PS, Sevim Erol A, Arıcı G (2017) Comparison of Bimaxillary Permanent Canine Arch Width in Terms of Human Sex Identification for Metric Analysis of Bite Marks. J Anthropology Rep 2: 116.

$7.81 \mathrm{~mm}$. This means $63 \%$ of this dimension is undefinable, but $37 \%$ can be identified.

In this study, the standard deviation of the maxillary (ICD) data in males was found to be larger, due to the variation between the (ICD).

\section{Discussion}

Bite marks analysis are usually performed by the method of superimpositioning the dental cast with the copies of bite marks where metric analyzes are essential. Although bite marks are reliable evidences for personal identification it has been reported that indirect measurements taken from the dental casts are $0.1 \mathrm{~mm}$ wider than the direct tooth measurements and it should be noted that approximately $0.1 \mathrm{~mm}-1.2 \mathrm{~mm}$ tolerance exists between the skin bite, dental model, wax bite, photograph and computer scanned image [13,14]. The other important issue for measurements is the axis angle of the canine tooth, the apex of this teeth may be located outwardly as seen in Figure 3.

The arch size between the maxillary canines were reported to be 2.1 to $4.1 \mathrm{~cm}$ in adults $[7,15]$. In our study, the arch size between the maxillary canines was $3.0-3.7 \mathrm{~cm}$ for females, $3.3-4.1 \mathrm{~cm}$ for males, and the arch size between the mandibular canines were: $2.0-3.0 \mathrm{~cm}$ for females, $2.2-3.2 \mathrm{~cm}$ for males, which was dimorphic to a certain extent.

Tooth dimorphism is specific for populations. The cases of this study were from Turkish population and Turkey is a country where genetic features are mixed within time due to its geographical location. This research revealed that there is an overlap between the teeth dimensions of sexes based on the small male teeth as well as large female teeth. These are the intersection areas where sex cannot be detected from the teeth.

\section{Conclusion}

According to the results of this research; except for the intersection regions, the ratio of bimaxillary permanent inter canine arch width for both male and female can be determined in the measurement areas as $59 \%$ for maxilla and $37 \%$ for mandibula. Therefore maxillary inter canine arch width is a preferable data which may provide ease for the forensic identification analysis of bite mark evidences before performing the DNA analysis. The establishment of dental data for each country, may provide great convenience to access correct and quick results for international legal cases.

\section{Acknowledgements}

We would like to express our sincere appreciation to experts, Bahar Aka MSc and Esmahan Arıcı BSc, respectively from the field of economy and statistics, for supporting this work with their knowledge and interpretation.

\section{References}

1. Stavrianos $C$, Aggelakopoulos $N$, Stavrianou $P$, Pantelidou $O$, Vasiliadis $L$, et al. (2011) Comparison of Human and Dog Bite Marks. Journal of Animal and Veterinary Advances 10: 2649-2654.

2. OECD Database (2017)

3. Aka PS, Yagan M, Canturk N, Dagalp R (2015) Primary Tooth Development in Infancy, A Text and Atlas, CRC Press, Taylor \& Francis Group.

4. Harris EF, Nweeia MT (1980) Tooth size of Ticuna Indians, Colombia, with phenetic comparisons to other Amerindians, Am J Phys Anthropol 53: 81-91.

5. Tarvadi P, Manipady S, Shetty M (2016) Intercanine distance and bite mark analysis using metric method Egyptian Journal of Forensic Sciences 6: 445-448

6. Barsley RE (1993) Forensic and legal issues in oral diagnosis. Dent Clin North Am 37: 133-156.

7. Bernstein ML (1997) Forensic dentistry. Overview of forensic dentistry. J Okla Dent Assoc 88: 18-28.

8. Kashyap B, Anand S, Reddy S, Sahukar SB, Supriya N, et al. (2015) Comparison of the bite mark pattern and inter canine distance between humans and dogs. Journal of Forensic Dental Sciences 7: 175-179.

9. Iscan MY, Kedici PS (2003) Sexual variation in bucco-lingual dimensions in Turkish dentition. Forensic Sci Int 137: 160-164.

10. Sharma M, Gorea RK (2010) Importance of mandibular and maxillary canines in sex determination. JPAFMAT 10: 27-30.

11. Yuwanati M, Karia A, Yuwanati Mn (2012) Canine tooth dimorphism: An adjunct for establishing sex identity. J Forensic Dent Sci 4: 80-83.

12. Al Rifaiy MQ, Abdullah MA, Ashraf I, Khan N (1997) Dimorphism of mandibular and maxillary canine teeth in establishing sex identity. The Saudi Dental Journal 9: 17-20

13. Hunter WS, Priest WR (1960) Errors and discrepancies in measurement of tooth size. J Dent Res 39: 405-414.

14. Atsu SS, Gokdemir K, Kedici PS, Ikyaz YY (1998) Bitemarks in forensic odontology. J of Forensic Odontostomatol 16: 30-34.

15. Sweet D, Pretty IA (2001) A look at forensic dentistry-Part 2: Teeth as weapons of violence-identification of bitemark perpetrators 190: 415-418. 